\title{
À sombra de Júlia: atritos do traduzir
}

\author{
Álvaro Faleiros
}

O intuito desta reflexão é discutir alguns momentos-chave da tradução do livro infantojuvenil Histoire de Julie qui avait une ombre de garçon para o português. Esse clássico da literatura infantil francesa trata com delicadeza das diferenças de gênero e da descoberta da sexualidade.

No livro, conta-se a trajetória de uma menina que, de tanto ouvir seus pais dizerem que tinha os trejeitos de um menino, um dia percebe que a sombra dela se transformou, adquirindo justamente a forma de um menino. Entristecida e sem compreender muito bem o que se passa consigo, ela começa a questionar sua própria identidade e se precisará modificar seu jeito de ser para se livrar do estigma. Escrito numa linguagem altamente poética, na qual há passagens em versos, o livro propõe para o público infantojuvenil uma bela reflexão sobre a sexualidade e o preconceito.

As questões envolvidas na reescrita desse clássico são, pois, de dupla natureza. Deve, por um lado, considerar a especificidade do público e, por outro, a dimensão poética desse texto no qual se entretecem momentos em prosa, em versos e na forma de diálogos. Retomando o título de um artigo recente de Paulo Henriques Britto dedicado à publicação no Brasil de Hughes e Eliot para crianças, o desafio é praticar "a dupla arte de traduzir poesia". Como lembra Britto no referido artigo, ao comentar a tradução de "Os Gatos" de Eliot, "traduzir esses poemas não é tarefa fácil. O tradutor é pressionado em dois sentidos contrários", ele deve levar em conta que se trata de um livro para crianças e não perder de vista que também são poemas.

Para orientar a análise aqui proposta, é necessário fazer algumas breves considerações sobre o ato de traduzir. Com efeito, a passagem de 
qualquer texto de uma língua para outra é sempre uma operação complexa. É certo também que o grau de complexidade pode variar em função das diferenças culturais e linguísticas, das diferenças editorais e de recepção, das diferenças de gêneros. No que concerne a literatura infantojuvenil pode-se verificar que, em grande medida, a especificidade do público cumpre um papel determinante; o que faz com que se utilize, com frequência, o termo "adaptação" quando se trata desse tipo específico de passagem. Tanto é que, conforme registra Lauro Amorim (2005, p. 55), "a maioria das adaptações, na atualidade, é vinculada a um determinado público, como o infantojuvenil".

Não se trata aqui de retomar a profícua e controversa discussão sobre as fronteiras entre tradução e adaptação. É suficiente aqui assinalar, seguindo os passos de Bastin (1990), em seu artigo "Traduire, adapter, reexprimer" que "a adaptação é fundamentalmente um processo de reexpressão" (p. 471), processo este que, como aponta, desta vez Gambier (1992, p. 421-2), é mediado "pelo processo social, cultural, que consiste em agir de acordo com as normas dominantes, em harmonizar-se com elas, em integrar-se a uma nova rede de solidariedade, de valores".

A harmonização com uma determinada rede de valores pode significar tanto uma escolha puramente moral, como uma escolha estética.

No caso de Histoire de Julie qui avait une ombre de garçon, o título já possibilita uma primeira discussão. Uma possível tradução semântica do título seria "História de Júlia que tinha uma sombra de menino". Ora, como foi mencionado acima, a escrita do livro é delicada e linguisticamente motivada. Optou-se, pois, por uma tradução em que a respiração do texto fosse mais sugestiva. $O$ resultado "A história de Júlia e sua sombra de menino" agradou aos editores e foi adotada devido à leveza e sinuosidade das aliterações em [s], ainda que estas não estivessem presentes no texto de partida.

Houve, porém, um momento em que a conformidade com as normas levou a uma atenuação das imagens. Lê-se no texto em francês:

Ce soir, Julie est découragée. Et si c'était l'ombre qui avait raison. Elle n'est peut-être qu'un garçon... manqué en plus, avec cette fente entre les cuisses qu'elle aime bien toucher doucement.

O trecho acima foi primeiramente traduzido por: 
Esta noite Júlia está desanimada. E se a sombra estiver certa? Talvez ela não passe mesmo de um menino... mas não um menino de verdade, o que é pior, além do mais, com essa fenda entre as coxas, que ela gosta de tocar suavemente.

Um primeiro aspecto que chama a atenção é a expressão garçon manqué, que significa um "menino que não deu certo". A inexistência de uma expressão com sugestividade homóloga em português levou à sua tradução pela expressão "não é um menino de verdade", ou ainda "parece um menino". A grande questão, contudo, era a "fenda entre as coxas" e o desejo que a envolve. Por soar grosseiro para o potencial público-alvo do livro, essencialmente formado por pais e professores brasileiros, a "fenda entre as coxas, que ela gosta de tocar suavemente" acabou sendo substituída por:

Esta noite Júlia está desanimada. E se a sombra estiver certa? Talvez ela não passe mesmo de um menino... mas não um menino de verdade, o que é pior, pois nesse caso ela teria algo diferente entre as pernas. E isso ela não quer.

Ficou a afirmação da diferença de gêneros e a vontade de manter o que se tem entre as pernas, entretanto, a dimensão do desejo foi omitida para uma maior adequação às normas vigentes. Os dois exemplos acima corroboram a afirmação de Bastin, retomada por Amorim quando este afirma que a adaptação é, "curiosamente, um desvio que torna possível a superação de outros desvios" (Amorim, 2005, p. 89). Isto é, se, por um lado, o fato de se tratar de um texto destinado a um público que, por razões morais, recorre à edição, passando por omissões; por outro, essa liberdade permite a busca de uma plasticidade maior, como ocorreu no título.

No caso específico da História de Júlia, a própria escrita do texto abriu caminhos interessantes para a reescrita. Em uma das primeiras páginas do livro, Júlia é apresentada por meio de um poema que se inicia da seguinte maneira:

Julie n'est pas polie elle suce encore son puce Julie est très Julie mais voudrait être rousse 


\section{Julie n'est pas très douce \\ elle n'aime pas les peignes \\ et se cache sous la mousse \\ pour ne pas qu'on la baigne}

Nessas duas primeiras estrofes, surge o olhar crítico dos pais, pois ali Júlia não é nem "educada" (polie), nem "muito doce" (très douce). Como se não bastasse, ela "ainda chupa o dedo" (suce encore son puce) e não gosta nem de se pentear (n'aime pas les peignes), nem de tomar banho (se cache sous la mousse pour ne pas qu'on a baigne). A graça da descrição reside tanto na inusitada vontade de Júlia de ser ruiva (mais voudrait être rousse), quanto no fato de a curiosa descrição ser na forma de quadrinhas populares rimadas.

Uma análise formal do poema aponta para uma aparente isometria. A primeira estrofe, por exemplo, pode metricamente ser interpretada da seguinte maneira

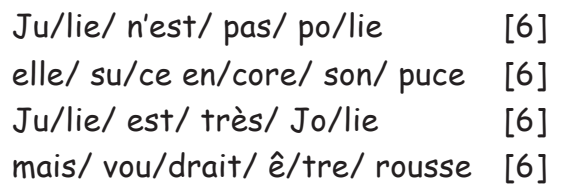

Ju/lie/ est/ très/ Jo/lie

mais/vou/drait/ ê/tre/ rousse

Essa interpretação, pautada na oralidade, desconsidera o fato de que, em francês, a contagem métrica inclui os " $e$ "s aparentemente mudos. Assim, no segundo verso, tem-se:

\section{elle/ su/ce/ en/co/re/ son/ puce [8]}

O detalhe pode parecer irrelevante, mas mostra que a métrica é incorporada de forma não canônica, não sendo, portanto, um elemento rígido na construção do poema. Tanto é que, na estrofe seguinte, no segundo e terceiro versos "elle n'aime pas les peignes" e "et se cache sous la mousse", adota-se a mesma liberdade. Essa mobilidade foi explorada na tradução, levando à seguinte reescrita dos quartetos:

Júlia não é lá muito gentil

e ainda por cima chupa o dedo, 
Júlia é linda, mas onde se viu,

queria ter os cabelos vermelhos!

Júlia não é lá muito mansinha,

nunca gostou de se pentear,

vive se escondendo na espuma

só para não ter de se banhar.

$O$ incomum eneassílabo foi escolhido por permitir um espaçamento do sentido. Bastante próximo do canônico decassílabo que, aliás, aparece no verso "queria ter os cabelos vermelhos" acaba soando natural devido à liberdade sintática que permitiu. Por exemplo, a introdução das expressões "não é lá" e "mas onde se viu" reforçam a dimensão oral que, no caso do texto francês, é evidente pelo apagamento dos " $e$ " $s$. $O$ "mas onde se viu" produz também uma rima puramente oral com "gentil", contribuindo para o registro falado da história contada.

A rima toante de "dedo" com "vermelho", e as associações sonoras mais livres entre "mansinha" e "espuma" foram recursos utilizados com intuito semelhante. Caso se quisesse "forçar" a rima, seria provavelmente necessário optar ou pelo apagamento das imagens, ou por inversões sintáticas incomuns nesse tipo de contexto enunciativo.

Há ainda outros exemplos interessantes como a saturação paronomásica dos versos:
Quand une ombre
un peu trop sombre
vous suit comme
votre ombre,
nom d'un concombre,
elle vous encombre.

A escolha, em francês, do vocábulo concombre (pepino) parece se dever essencialmente a um jogo sonoro, motivo pelo qual, ao invés de se procurar equivalentes semânticos, optou-se pela seguinte reescrita rítmica e melódica:

Quando uma sombra,

sombria demais, 
segue você, como

sua própria sombra,

e em você ela até tromba,

isso de fato assombra.

O "nom d'un concombre" (nome de um pepino) torna-se "e em você ela até tromba". Assim como, "elle vous encombre" (ela vos enche), transmutado em "isso de fato assombra". O primeiro desses versos perde um pouco de seu gracioso nonsense, entretanto, o caráter lúdico da saturação sonora sustenta a estrofe em português, ainda que o caráter sombrio se adense, o que condiz com o tom do livro.

O drama vivido por Júlia, que é perseguida por uma sombra de menino ao longo da narrativa, é um tema sombrio. Tanto é que, em um de seus momentos de maior melancolia, o narrador diz a Júlia:

Jolie Julie, la nuit,

de ses yeux grands ouverts

dessine pour demain

des matins sans soleil.

Ou seja, um regime noturno domina, é a noite que está de "olhos bem abertos" (yeux grands ouverts) e o que ela "desenha para amanhã" (dessine por demain) são "manhãs sem sol" (des matins sans soleil). Nesta, que é uma das mais belas passagens do livro, o texto se condensa por meio de finas homofonias como "Jolie Julie, la nuit", ou ainda pela assonância entre "ouverts" e "soleil". A língua portuguesa permitiu também a construção desta intensa rede fonossemântica:

Minha linda Júlia, veja só,

quem dera a noite abrisse seus olhos

e desenhasse para o futuro

manhãs sem sol.

Na estrofe, as homofonias de "Jolie Julie, la nuit" ecoam em "Minha linda Júlia" e a assonância entre "ouverts" e "soleil" desdobra-se nas rimas entre "só", "olhos" e "sol". 
A ideia do desdobramento parece ser uma bela imagem para se pensar o trabalho de reescrita aqui realizado, pois, assim como o texto traduzido, a sombra de Júlia não é mais a própria Júlia, chegando a mudar de gênero e fazendo de sua individualidade algo mais complexo. Se é certo que a descoberta desse outro que se cola ao sujeito assusta, esse outro também o revela, ainda que seja por uma certa negatividade. E este é justamente um dos grandes paradoxos de todo ato tradutório, queira-se ele "adaptação" ou não.

Mas para não restringir o ato de traduzir à sua dimensão melancóli$\mathrm{ca}$, vale apontar para o fato que quando se lida com uma reescrita como a infantojuvenil, a natureza adaptativa que muitas vezes acompanha esse trabalho faz com que o grau de inventividade que daí decorre seja consideravelmente maior. Johnson (1984), em Translation and adaptation, comenta, por exemplo, que a adaptação seria "mais flexível e daria mais espaço para modificações, subtrações e acréscimos ditados pelo formato do texto de chegada" (p. 421).

No final do livro, após se ter perdido na cidade, numa luta desesperada para fugir de sua sombra e ter encontrado um amigo que também se sentia incompreendido, Júlia volta para casa, afirmando que ela tem o direito de ser o que é. Aquilo que a conforma é resumido na seguinte fórmula que encerra o livro:

\section{Julie-chipie \\ Julie-furie \\ Julie-Julie}

Júlia assume-se, assim, respectivamente, uma "pentelha", ou uma "provocadora" (Julie-chipie), uma "furiosa" (Julie-furie), para finalmente afirmar-se Julie-Julie. A identidade entre Júlia e suas características deve-se também aos ecos sonoros do nome da personagem nos adjetivos que a qualificam, o que levou à seguinte reescrita:

Júlia-fagulha

Júlia-fúria

Júlia-Júlia

Transpor furie por "fúria" foi bastante simples e evidente. $O$ desafio foi, sobretudo, reescrever o primeiro termo Julie-chipie, pois chipie, 
em francês, é normalmente utilizado para se referir a uma velha senhora cheia de manias e, de certo modo, provocadora. O que guiou a escolha por "fagulha" foi a possibilidade de evocar simultaneamente uma dimensão sonora e imagética. Se é certo que o termo "fagulha" não retoma imediatamente o lado "chato" da personagem, também o é que a dimensão provocadora de Júlia salta aos olhos, iluminando-a, ainda que por um átimo, ainda mais. O revés da sombra melancólica que envolve o ato de traduzir aí se encontra: do mesmo que nossa Júlia-fagulha, aquele que reescreve com a liberdade de quem pode adaptar consegue produzir uma outra luz, uma faísca que só provém do atrito.

\section{Referências}

AMORIM, Lauro. Tradução e Adaptação. São Paulo: UNESP, 2005.

BASTIN, Georges L. Traduire, adapter, reexprimer. Meta, Montreal, 35.3, 1990.

BRITTO, Paulo Henriques. A dupla arte de traduzir poesia. 26 de setembro de 2010, Caderno Ilustríssima, Folha de São Paulo.

BRUEL, Christian; GALLAND Anne. Histoire de Julie qui avait une ombre de garçon. Paris: Edition Etre, 2009.

A história de Júlia e sua sombra de menino. Ilustrações Anne Bozellec. Tradução Álvaro Faleiros. São Paulo, Scipione, 2010.

GAMBIER, Yves. Adaptation: une ambigüité à interroger. Meta, Montreal, 37.3, 1992.

JOHNSON, M. A. Translation and adaptation. Meta, Montreal, 29.4, 1984. 